\title{
Disparities in public protection measures against sexual offending in England and Wales: an example of preventative injustice?
}

\author{
Kirsty Hudson Cardiff University, UK \\ Andrew Henley Keele University, UK
}

\begin{abstract}
This article analyses the use of criminal justice measures aimed at the prevention of sexual offending across England and Wales. Specifically, it focusses on measures such as the 'sex offenders register' and sexual offences prevention orders (SOPOs) and the use of sanctions for their breach. Following a discussion of the apparent tensions between individual rights and public protection measures we present an original analysis of data collated from Multi-Agency Public Protection Arrangement (MAPPA) area reports over a nine-year period. Our analysis reveals considerable variation between areas in both the risk-level allocation of cases, the imposition of SOPOs and sanctions for non-compliance with MAPPA. We argue that these disparities raise issues concerning both the rights and autonomy of those subjected to public protection measures and highlight the need for further detailed research into MAPPA practices.
\end{abstract}

\section{Key words}

Human rights, public protection, sexual offending, preventative justice, MAPPA, SOPOs

\section{Introduction}

Over the last two decades a raft of punitive legislation intended to manage the risks posed by 'known sexual offenders' has developed. This has included the introduction of supervisory oversight and monitoring of individuals in the community post-sentence 
through the 'Sex Offenders Register' ${ }^{\text {' }}$ and Multi-Agency Public Protection Arrangements, or MAPPA ${ }^{2}$ (Thomas 2011; Stone 2012). The general trend has been for interventions to be 'strengthened', 'toughened' and 'tightened' (Thomas 2008), notably through the Sexual Offences Act 2003 and more recently by the Sexual Offences Act 2003 (Notification Requirements) (England and Wales) Regulations 2012 ${ }^{3}$. Part 2 of the Sexual Offences Act 2003, for example, introduced a range of new civil preventative orders. These included: the sexual offences prevention order (SOPO), which replaced the sex offender order (introduced by s.2 of the Crime and Disorder Act 1998); restraining orders (introduced by s.66 of the Criminal Justice and Court Services Act 2000); foreign travel orders, which impose travel restrictions on registered sex offenders $\left(\mathrm{RSOs}^{4}\right)$; and risk of sexual harm orders, which can be imposed on persons who have no convictions of any kind (Shute 2004). Additionally, the Child Sex Offenders Disclosure Scheme allows for information about RSOs to be shared with the public through controlled disclosure (see Kemshall and Wood 2010; Kemshall et al. 2012; Chan et al. 2010).

Recent changes made in the Anti-social Behaviour, Crime and Policing Act 2014 widens the use of such orders so that they can be used to manage the risk against adults as well as children. For example, a new Sexual Harm Prevention Order will replace the Sexual Offences Prevention Order and Foreign Travel Order; and the Sexual Risk Order (SRO) has replaced the Risk of Sexual Harm Order. Due to the civil nature of these 
orders, the standard of proof required for their imposition is based on the balance of probabilities (their jurisdictional application and related debates surrounding the subject's rights will be discussed later in the paper). They then essentially entail the use of what Kemshall and Maguire (2002:14) have termed 'negative conditions' to restrict and control the subject's behaviour in the community. All carry criminal penalties should they be breached, including up to 5 years imprisonment (Knock et al. 2002; Shute 2004). While designed to limit and monitor the behaviour of particular individuals in the interests of public protection, the gravity of these potential consequences for RSOs clearly underscore the importance of accurately evaluating their future risk of offending.

Currently, MAPPA oversees the assessment and management of 'high risk' individuals, notably RSOs (Thomas 2011; Stone 2012). MAPPA utilises an inter-agency approach to the operational practices involved in the risk assessment, supervision, surveillance, intervention with, enforcement, compliance, and breach of, purportedly 'high risk' cases. A three-tiered risk management system (ranging from Levels 1 to 3 ) is used to target resources at those perceived as posing the highest level of risk (Level 3). The risk level of the individual therefore determines the degree of restrictive, rehabilitative and protective interventions put in place to manage risk, and the extent to which information is shared between the agencies involved in MAPPA. The Home Office and latterly the Ministry of Justice (MoJ) have issued various guidance manuals to MAPPA (e.g. MoJ 
2007; 2012) and subsequent evaluations of the public protection arrangements have been conducted which outline the risk management procedures used in relation to RSOs (e.g. Maguire et al. 2001; Kemshall et al. 2005; Wood and Kemshall 2007; see also Kemshall 2008; Wood and Kemshall 2008). An area of concern that has been given increasing recognition is the need for consistency in practice across the different 42 MAPPA areas in England and Wales. In particular, the need to ensure that all RSOs are allocated to the appropriate level of risk management and that the imposition and use of SOPOs during this time was appropriate. Similar concerns over consistency were also raised by Hudson et al. (2015). These findings highlighted an uneven distribution of RSOs and variations in risk-level allocations both geographically (between the 42 MAPPA areas) and over time (from 2004/5 to 2010/11), again raising a number of concerns about the fairness of MAPPA practice.

The primary purpose of this paper is to examine further the incidence of RSOs alongside the use and consistency of preventative measures against further offending. Specifically this paper is interested in the use and consistency of the SOPO ${ }^{5}$, as well as the use of sanctions relating to the breach of SOPOs and the notification requirements. The primary data used in this analysis were derived from the annual reports for the 42 designated MAPPA areas in England and Wales over a nine-year period, from 2004/5 to 
2012/13. We have therefore been able to examine consistency in the use of SOPOs over time and geographically.

The remainder of this paper is structured in the following four ways. First, we examine in more detail a number of human rights concerns over the use of such preventative measures, specifically the notification requirements and the SOPO. Second, we describe how the data were collated and prepared for analysis. Third, we present the findings from fairly straightforward analyses of the data before, fourthly, discussing important insights into future practice and research.

\section{Just social policies versus public protection}

Numerous legislative responses have been introduced to protect the public and curb rising community concern about the release of convicted sexual offenders. Yet the rate of sexual reconviction for sexual offenders is known to be comparatively low, typically 10 per cent to 15 per cent after five years (Bates et al. 2003; Harris and Hanson 2004; Hanson and Morton-Bourgon 2005; Hoare and Jansson 2008; Kershall et al. 2008). Reconviction as an outcome measure, of course, fails to take into account unofficial levels of sexual re-offending (Falshaw et al. 2003), high attrition rates and/or difficulties in prosecution proceedings (Kelly et al. 2005; Taylor and Gassner 2010). Accordingly

researchers now recommend the use of other outcome measures to supplement 
reconviction data (Falshaw et al 2003). Similarly, it is accepted that research examining repeat offending of convicted sexual offenders should also take into account the offence characteristics of different subtypes of sexual offenders (Craig et al. 2003; Smallbone et al. 2008; Finkelhor 2009; Butler et al. 2012) as well as the impact of any intervention or management strategies (Stalans 2004; Hanson et al. 2009; Brown 2010; Peck 2011; Butler et al. 2012) which have been shown to account for differences in recidivism rates.

Despite these methodological challenges, the observed recidivism rate is 'less than commonly believed' (Mann et al. 2010: 192). Thus MAPPA and the associated measures that supervise, control and monitor RSOs in the community have been extensively criticised for responding to an over-exaggerated level of risk reflecting the 'Othering' of those convicted of sexual offences. This has largely been attributed to the concept of 'populist punitiveness' (Bottoms 1995: 40) in addition to the influence of the media who stand accused of inflating public awareness, concern and fear of sexual offending within the narrow stereotypes of 'stranger' and 'predator danger' (see inter alia Cobley 2000; Greer 2003; Brayford and Deering 2012). Indeed, the increased policy focus on sexual offending during the 1990s led Soothill et al. (1998) to coin the phrase 'criminal apartheid' to account for the way in which sexual crimes were differentiated from other forms of offending. This trend has evidently continued with few other offence-groups ${ }^{6}$ having been singled out in such ways (Blandford \& Beech 
2011). The appropriation of criminal justice resources based on public demand and/or media recommendations (see Critcher 2002) has been extensively criticised for failing to meet the real needs of current or future victims (see Greer 2003; Kitzinger 1999, 2004a, 2004b). Of interest to this paper, is how policies based on so-called 'precautionary logic' (see Ericson 2007; Hebenton and Seddon 2009) neglect to take into account an RSO’s basic rights.

Many of the measures cited above have previously been regarded as acceptable due to their aim at ex ante prevention of crime rather than ex post punishment (see Schauer 2013). However, this argument is being challenged due to the increasing severity of measures being regarded as effectively imposing or increasing further punishments which extend the original sentence. Thomas (2008) questions whether the 'sex offenders register', which is supposedly not a 'punishment for a sexual offence [nor] part of the system of penalties’ (Home Office 2012a: 9), now, due to numerous changes since its introduction, constitutes a punishment in its own right. Indeed, when introducing these changes, the Home Office stated that current registrants were 'required to comply with all requirements of the notification regime, including the new matters set out in the Sexual Offences Act 2003 (Notification Requirements) (England and Wales) Regulations 2012' (2012b: 1; emphasis added). This included a reduction in the number of days an individual had to make initial and subsequent notifications, a requirement to provide identification at each notification (including finger prints and photographs), the 
requirement to notify any address at which they stayed for more than twelve hours where a child aged under 18 resided and the requirement to provide details of their bank accounts. Failure to comply with these new requirements constitutes a separate criminal offence punishable by up to five year’s imprisonment (Home Office 2012b: 1).

This opens up current legislation to a number of human rights concerns and possible breaches of the European Convention of Human Rights (ECHR), which is enshrined into domestic law through the Human Rights Act 1998. The retrospective nature of the changes outlined above raises important questions regarding their ex post facto nature and whether they in fact breach article 7 (on 'retroactivity') and article 8 (on 'the right to respect for privacy and family life') of the ECHR. Following article 8.2, where measures aimed at improving 'public safety' or 'the prevention of disorder or crime' are not 'necessary in a democratic society', they may become susceptible to challenge ${ }^{7}$. Domestic courts appear to have reached the position that whilst inclusion on the 'sex offender register' engages article 8 it does not necessarily breach it (see Thomas 2011: 76-79). However, more recent case law has challenged the requirement that those sentenced to 30 months or more for a qualifying offence are automatically placed on the register for life. In April 2010, the UK Supreme Court ruled ${ }^{8}$ that individuals so effected must be given the opportunity to apply for their names to be removed from the register, arguing that lifetime inclusion without the right of review was a violation of article 8 . Consequently, the Home Office have introduced a review mechanism, albeit only after 
15 years inclusion on the 'register' and within the context of the new more stringent measures just discussed. While the lawfulness of the review mechanism may well be questioned further, the government's position remains that the new amendments do not breach human rights law (Home Office 2012b: 1).

Similar rights and proportionality arguments arise when discussing the use and impact of the civil order introduced in the Sexual Offences Act 2003. A SOPO is available to the courts when sentencing an individual for an offence listed in schedule 3 or schedule $5^{9}$ of the Sexual Offences Act 2003, or on the application of the police in respect of a person who has previously been dealt with for such an offence. Under a SOPO an individual will (if not already) become subject to the notification requirements and be subject to restrictions on their behaviour - for instance, prohibition from having unsupervised contact with children or from refusing police access to Internet-enabled devices in their possession in order to examine the content. The minimum duration of a SOPO is five years, but orders can be made for an indefinite period of time and therefore can remain in place until discharged, varied or renewed by the courts. Whilst a court cannot discharge an order within five years (without the consent of both its subject and the chief police officer from the relevant area) it has become the accepted position of the appeal courts ${ }^{10}$ that the duration of a SOPO should match the duration of the notification requirements imposed. This applies particularly where an order is being made at the same time as the sentencing for an offence. 
Section 104 of the 2003 Act, under which applications for a SOPO are granted, contains the statutory 'test' that the imposition of an order should occur only when 'there is $a$ reasonable cause to believe that an order is necessary to protect the public, or individual members of the public, from serious sexual harm,11 (Home Office 2012a: 44; emphasis added). Moreover, 'a key factor to be considered is the risk presented by the defendant' with the risk, in this context, based on 'the likelihood of the offender committing a sexual offence; the imminence of that offending; and the seriousness of the harm resulting from it' (Home Office 2012a: 44). Thus a SOPO, and ultimately its intrusive content, is imposed based upon a prediction of future behaviour. This risk assessment is undertaken throughout an RSO’s sentence using risk assessment tools such as the Offender Assessment System (OASys), actuarial measures such as Risk Matrix 2000, Structured Assessment of Risk and Need (SARN) for those in treatment programmes and, in the case of juveniles, ASSET. The most widely used actuarial riskassessment tool for sexual offenders in the English and Welsh Prison and Probation Services is the Risk Matrix 2000 (Thornton et al. 2003).

The accuracy and predictive validity of actuarial instruments and the appropriateness of their use in predicting future offending has been widely debated and researched (see for example, Craig et al. 2006; Craig et al. 2008; Hanson and Morton-Bourgon 2009; Barnett et al. 2010). Current findings suggest that actuarial assessments outperform 
unstructured clinical judgment with regard to assessing risk of recidivism (Hanson and Morton-Bourgon 2009). Accordingly, Barnett et al. (2010: 23), as with previous studies, found that the RM2000/S had 'moderate predictive accuracy as a measure of relative risk, with a range of sexual offenders'. However, actuarial methods are not without their critics. Concerns over fairness immediately emerge from the possibility of false-positive outcomes when attempting to predict serious future offending amongst those subject to public protection measures. False-positives, or wrongly predicting that an individual poses a 'high risk of re-offending', arguably threaten the article 8 'right to private and family life' when such predictions lead to the imposition of measures (e.g. SOPOs) aimed at reducing any perceived risk. These arguments can equally apply to the imposition of notification requirements. It is worth remembering that the penalty for breaching such measures is a custodial sentence of up to five years.

Whilst actuarial measures are favoured, a number of other sexual offender risk measures continue to be used. Questions therefore remain as to how to interpret different results from various risk assessment tools (Hanson and Morton-Bourgon 2009) and the role of professional judgment. Given the high stakes for RSOs, it is imperative that the assessments being used are as accurate as possible. It is therefore essential that research continues to examine each tool's ability to measure relative risk, the purpose of risk assessments, and the role of professional judgment, in order to ensure that restrictive 
measures put in place to manage those considered a higher risk of reoffending are applied fairly, consistently and only where strictly 'necessary'.

\section{Data and methodology}

The data used within this paper were derived from MAPPA annual reports. These reports provide the public with information on how MAPPA operates and present statistical information on the individuals monitored across various risk-level categorisations. For the period 2004/5 to 2010/11 the annual reports were accessed via the MoJ website and from the websites of the relevant police force or probation service for each area. Since 2010/11, this information has been collated centrally by the MoJ therefore centralised data were used to extend the time period to 2012/13. The data used within this paper thus covers a nine-year period from 2004/5 to 2012/13.

Statistical information relating to 'Category One' cases (RSOs) was collated for each of the 42 MAPPA areas. This included the number of RSOs under MAPPA and the number of RSOs managed at Level 2 and Level 3 of the arrangements (from which the percentage managed at these 'high' and 'critical risk' levels was calculated). It also includes the number of RSOs convicted or cautioned for breach of the notification requirements, the number of full SOPOs imposed by the courts, and the number of Level 2 and 3 RSOs sent to custody for breaching a SOPO (although as we explain below these are not all presented as 'raw' figures). 
It is important to note that the data represents the number of cases included on $31^{\text {st }}$ March for each corresponding year, like a form of census data. The total number of cases that were managed may have fluctuated between each census date. The same also applies to the risk-level allocation of RSOs, SOPOs and breach figures. Crucially however, the same census date was used consistently across all 42 MAPPA areas. Slight differences were observed for the period 2004/5 to 2010/11 when comparing data extracted from individual MAPPA area reports with official national statistics provided by the MoJ. These minor differences can possibly be explained by timing differences in the recording of these data, and due to the outcome of some convictions or cautions being overturned at a later date on appeal. For the majority of statistics, however, the number of RSOs over the nine-year period was broadly consistent with the figures provided within annual MoJ statistical bulletins.

Reported MAPPA data only provides total figures for each area across different measures such as the actual number of SOPOs imposed or RSOs convicted and cautioned for breaching notification requirements in each area. Given the large disparity in the number of RSOs managed in different areas these figures were not directly comparable between or across areas. This is because certain MAPPA areas cover much larger numbers of people in the population generally, for instance London and the West Midlands areas. In this paper, we therefore reproduce the total number of RSOs managed by MAPPA each year across England and Wales as a whole. We also 
reproduce nationwide data on risk-level allocation, as a percentage of RSOs managed at levels 2 and 3 of MAPPA, per year, as well as on the use of preventative measures against sexual offending and sanctions for their breach as relative annual rates, i.e. per 100 RSOs, per year. The use of proxy measures based on relative rates allowed for correlations to be calculated between these measures using Pearson product-moment correlation coefficients $(r)$.

Our research does not therefore report actual numbers of RSOs, preventative measures and sanctions for their breach in each area. The reasons for this are twofold. Firstly, without standardising the data in this way, as stated above, comparisons between the different MAPPA areas are meaningless. Secondly, by not providing the actual numbers of RSOs in each area (or numbers of SOPOs imposed) we avoid 'sensationalising' the data since it is important to bear in mind that the actual number of RSOs in any given area is very small in relation to the size of the general population. Whilst these standardised figures, or rates, remain mostly descriptive, they allow for the comparison of inter-area consistency (and fairness) in the use of preventative justice measures aimed at reducing sexual offending.

\section{Analysis of MAPPA data on 'Registered Sexual Offenders'}

The following section presents findings from fairly straightforward analyses of the data which explores both the use of public protection measures over time and inter-area (in-) 
consistency. Table 1 provides data on the total number of RSOs across England and Wales between 2004/5 and 2012/13, risk-level allocation of $\mathrm{RSOs}^{12}$, the rate at which SOPOs have been imposed and sanctions for breaching them (in the case of 'higher risk' $\mathrm{RSOs}^{13}$ ) as well as the rate of convictions and cautions for those that breach the notification requirements. These data show trends across all 42 MAPPA areas in England and Wales combined. In Table 2 we then compare the management of RSOs between the 42 MAPPA areas in England and Wales across the nine-year period since the implementation of the Sexual Offences Act 2003. Table 2 also provides data on risklevel allocation, the relative rates at which SOPOs were imposed and the relative rate of sanctions for breaching the notification requirements on an area-by-area basis. These are presented as the nine-year mean rates based on the end of year calculations of those rates from 2004/5 to 2012/13.

Table 1: Numbers of RSOs and relative rates of the use of public protection measures in England and Wales over time (2004/5 to 2012/13)

\begin{tabular}{|c|c|c|c|c|c|}
\hline Year & $\begin{array}{r}\text { Total number } \\
\text { of RSOs } \\
\text { managed } \\
\text { under } \\
\text { MAPPA }\end{array}$ & $\begin{array}{r}\% \text { of RSOs } \\
\text { managed at } \\
\text { Level } 2 \text { or } 3 \text { of } \\
\text { MAPPA }\end{array}$ & $\begin{array}{r}\text { SOPOs } \\
\text { imposed } \\
\text { (per 100 } \\
\text { RSOs) }\end{array}$ & $\begin{array}{r}\text { Level } 2 \& 3 \\
\text { RSOs sent to } \\
\text { custody for } \\
\text { breaching a } \\
\text { SOPO (per } 100 \\
\text { RSOs at these } \\
\text { levels) }\end{array}$ & $\begin{array}{r}\text { Convictions or } \\
\text { cautions for } \\
\text { breach of } \\
\text { notification } \\
\text { requirements } \\
\text { (per } 100 \text { RSOs) }\end{array}$ \\
\hline $2004 / 5$ & 28,994 & 20.82 & 1.50 & 1.46 & 3.24 \\
\hline $2005 / 6$ & 29,983 & 20.79 & 3.06 & 2.58 & 3.85 \\
\hline $2006 / 7$ & 30,416 & 21.00 & 3.61 & 1.89 & 4.79 \\
\hline $2007 / 8$ & 31,392 & 18.30 & 4.50 & 1.68 & 4.55 \\
\hline $2008 / 9$ & 32,347 & 14.88 & 4.70 & 1.84 & 3.33 \\
\hline $2009 / 10$ & 34,939 & 5.84 & 5.31 & 6.59 & 3.55 \\
\hline $2010 / 11$ & 37,225 & 4.19 & 6.55 & 6.89 & 3.38 \\
\hline $2011 / 12$ & 40,345 & 2.98 & 6.56 & 10.59 & 2.90 \\
\hline 2012/13 & 43,664 & 2.24 & 7.02 & 14.56 & 2.99 \\
\hline
\end{tabular}


Table 2: Relative rates in the use of public protection measures across MAPPA areas in England and Wales (2004/5 to 2012/13)

\begin{tabular}{|c|c|c|c|}
\hline MAPPA Area & $\begin{array}{r}\% \text { of RSOs } \\
\text { managed at } \\
\text { Level } 2 \text { or } 3 \text { of } \\
\text { MAPPA }\end{array}$ & $\begin{array}{r}\text { SOPOs } \\
\text { imposed } \\
\text { (per 100 } \\
\text { RSOs) }\end{array}$ & $\begin{array}{r}\text { Convictions or cautions for } \\
\text { breach of notification } \\
\text { requirements (per 100 } \\
\text { RSOs) }\end{array}$ \\
\hline Avon \& Somerset & 12.62 & 6.45 & 1.32 \\
\hline Bedfordshire & 7.71 & 8.19 & 2.31 \\
\hline Cambridgeshire & 11.31 & 6.87 & 2.83 \\
\hline Cheshire & 22.93 & 4.14 & 1.42 \\
\hline County Durham & 6.00 & 7.73 & 3.16 \\
\hline Cumbria & 7.63 & 7.66 & 3.83 \\
\hline Derbyshire & 10.17 & 6.32 & 4.00 \\
\hline Devon \& Cornwall & 12.46 & 7.18 & 4.40 \\
\hline Dorset & 8.16 & 4.72 & 3.05 \\
\hline Dyfed-Powys & 17.42 & 4.14 & 2.85 \\
\hline Essex & 4.66 & 4.80 & 8.34 \\
\hline Gloucestershire & 13.47 & 6.94 & 3.14 \\
\hline Gt. Manchester & 4.79 & 3.05 & 3.22 \\
\hline Gwent & 8.41 & 4.81 & 3.83 \\
\hline Hampshire & 20.75 & 3.68 & 2.97 \\
\hline Hertfordshire & 8.98 & 7.41 & 4.53 \\
\hline Humberside & 5.52 & 6.89 & 3.45 \\
\hline Kent & 12.98 & 7.30 & 3.38 \\
\hline Lancashire & 5.43 & 6.49 & 7.09 \\
\hline Leics. \& Rutland & 7.63 & 3.35 & 3.16 \\
\hline Lincolnshire & 8.27 & 4.61 & 2.75 \\
\hline London & 29.64 & 1.64 & 8.65 \\
\hline Merseyside & 6.82 & 4.05 & 4.28 \\
\hline Norfolk & 5.62 & 4.18 & 1.88 \\
\hline North Wales & 17.23 & 6.57 & 3.76 \\
\hline North Yorkshire & 7.88 & 6.63 & 2.91 \\
\hline Northamptonshire & 9.16 & 6.22 & 2.91 \\
\hline Northumbria & 6.58 & 5.73 & 7.95 \\
\hline Nottinghamshire & 8.36 & 2.98 & 4.41 \\
\hline South Wales & 21.38 & 3.20 & 2.09 \\
\hline South Yorkshire & 6.17 & 4.20 & 1.91 \\
\hline Staffordshire & 18.35 & 3.11 & 2.02 \\
\hline Suffolk & 5.84 & 6.09 & 2.79 \\
\hline Surrey & 16.78 & 5.05 & 3.30 \\
\hline Sussex & 7.63 & 4.10 & 3.12 \\
\hline Teesside & 5.84 & 10.74 & 4.42 \\
\hline Thames Valley & 14.46 & 3.81 & 2.77 \\
\hline Warwickshire & 12.09 & 4.60 & 3.65 \\
\hline West Mercia & 7.95 & 5.21 & 4.50 \\
\hline West Midlands & 12.96 & 3.46 & 4.31 \\
\hline West Yorkshire & 4.89 & 8.80 & 2.92 \\
\hline Wiltshire & 9.30 & 4.93 & 2.19 \\
\hline
\end{tabular}


Table 1 clearly shows that the overall number of RSOs in England and Wales has steadily risen over the nine-year period in which the data were recorded (2004/5 to 2012/13). This is arguably indicative of the cumulative effect of long notification periods which in some cases are indefinite. Predictably, there are fewer individuals leaving the 'register' than are joining it. However, the data also shows a marked decrease in the proportion of RSOs being managed at the 'high' and 'critical' levels of risk (Levels 2 and 3). Accounting for this decrease in the overall number of 'higher risk' RSOs in England and Wales over a seven-year period, Hudson et at. (2015) acknowledge that this may have been the result of central guidance, including changes to the definition of the 'critical few' in 2003 (Home Office 2003) and/or a break from the initial 'precautionary principles', 'better safe than sorry' and 'defensive response' to the perceived risks of sexual offenders (Kemshall \& Wood 2008: 611). A further positive interpretation is that high-risk RSOs are being effectively managed through MAPPA, resulting in case management decisions to reclassify them as lower risk (Hudson et al. 2015). However, reiterating the questions posed in Hudson et al. (2015: 12); firstly, if any of these explanations were valid, would the decline in numbers be as dramatic as the analysis suggests? And secondly, why would the rate of decline vary so dramatically between MAPPA areas? Indeed, looking at this data over a nine year period (see Table 2) the average rate ranges from 29.64 in London down to only 4.66 in 
(neighbouring) Essex - or a proportion of 'higher risk' cases six times greater in London.

What is important to this study is that despite this consistent (and expected) increase in the total number of RSOs, the proportion of cases managed at Levels 2 and 3 has shown a marked decrease at the same time as a considerable increase in the rate at which SOPOs have been imposed across England and Wales. Table 1 clearly shows that the rate at which SOPOs have been imposed by courts has increased dramatically following their introduction in the Sexual Offences Act 2003. Critically, this increase is not attributable to overall changes in the number of RSOs managed under MAPPA as our figures show the relative rate at which SOPOs were imposed (per 100 RSOs, per year).

This trend may be a consequence of greater familiarity with the processes of applying for and imposing SOPOs amongst police and Crown prosecutors. It could also reflect the different points of time at which an order can be obtained, pointing to an increase in the use of a SOPO under s.104 (1) (a) of the Sexual Offences Act 2003. Here, the 'Relevant Chief Officer' can apply for an order after the date of conviction if 'satisfied that the defendant's behaviour since the appropriate date makes it necessary'. However, the relationship between the annual figures for the proportion of RSOs managed at levels 2 and 3 of MAPPA and the rate at which SOPOs were imposed by the courts shows a statistically significant negative relationship ( $\mathrm{r}=-0.91, \mathrm{p}<0.01)$. Whilst much 
needed clarification of the boundaries of 'necessity' when imposing SOPOs was provided in July 2012 by the Court of Appeal ${ }^{14}$, our data clearly underlines the need for further research into their use. Indeed, given that a SOPO lasts for a minimum period of five years, a large number of these orders are likely to be in place with lower risk RSOs managed at MAPPA level 1.

Table 1 also shows that the rate at which RSOs were convicted or cautioned for breaching the notification requirements increased steadily up until 2006/7 before beginning to decline. Historically, a higher proportion of RSOs being subject to more intensive 'risk management' seems to bear some relation (if not a strictly 'significant' one, $r=0.66, p=0.053$ ) to the rate at which convictions and cautions for breaching the notification requirements were dispensed. It should be noted that the highest rate of convictions and cautions coincided with the period when the highest proportion of RSOs was managed at levels 2 and 3, with a lower rate observed in recent years (when far fewer RSOs were managed at these levels). From 2008/9 onward a significantly lower proportion of RSOs have been managed at the more intensive management levels 2 and 3 which may account, to some extent, for the drop in the annual rate since breaches might be being detected less often due to the more infrequent contact with police public protection units (PPUs) amongst those RSOs previously managed at levels 2 or 3. 
This table also shows the rate at which level 2 and 3 RSOs were sent to custody for breaching a SOPO. The perceived increase in the rate at which custodial sentences have been passed for SOPO breaches from 2009/10 onwards is the result of a much smaller number of RSOs being managed at MAPPA levels 2 and 3. This has the effect of magnifying the rate in comparison to previous years. For this reason, it is difficult to ascertain whether responses to proven breaches have simply become more punitive or whether the reduction in the proportion of RSOs managed at levels 2 and 3 has enabled PPUs to be more effective in their policing of compliance with SOPOs. Given these difficulties, we have not included data on sanctions for SOPO breaches in the comparisons of inter-area consistency to which we now turn.

When comparing the rate at which SOPOs were used between the 42 MAPPA areas in England and Wales across the same time period (in Table 2) there is also evidence of inter-area inconsistency. Teesside for example, imposed orders at an average rate of 10.74 (per 100 RSOs, per year) whilst the comparable rate for London was only 1.64 . Therefore RSOs were, on average, more than six times more likely to have been made the subject of a SOPO (which could result in their imprisonment if breached) if they lived (or were sentenced) in Teesside than if they were in London. Rather incongruously given that they were statistically least likely to be subjected to a SOPO, RSOs in London were over six times more likely to receive a conviction or caution for breaching their notification requirement (8.65 sanctions per 100 RSOs, per year) than 
their counterparts in Avon and Somerset who were the least likely to be sanctioned for breaches (1.32 sanctions per 100 RSOs, per year).

There was no correlation between the average rates at which SOPOs were imposed across MAPPA areas with the average rates at which RSOs were convicted or cautioned for breaching the notification requirements $(\mathrm{r}=-0.04, \mathrm{p}=0.80)$. Nor was there any correlation between the average percentage of RSOs managed at the 'higher risk' levels 2 and 3 of MAPPA and the rate of breaches $(r=-0.03, p=0.85)$. Therefore, when comparing practice across areas, higher rates of sanctions for non-compliance with notification requirements did not appear to be linked to higher use of SOPOs or higher levels of RSOs assessed as posing a greater risk to the public. Interestingly, the rates at which SOPOs were used showed a significant but moderate negative correlation ( $\mathrm{r}=-$ $0.43, \mathrm{p}<0.01$ ) with higher reported average percentages of RSOs managed at levels 2 and 3. The opposite relation might have been expected with more 'high risk' RSOs being associated with more orders to protect against 'serious sexual harm.'

\section{Concluding remarks}

This research has examined the incidence of RSOs and the use of civil prevention orders with the intention of examining the extent to which these measures are being used consistently. Collating and utilising data published by the 42 MAPPA areas of England and Wales from 2004/05 to 2010/11, and MAPPA data collated centrally from 2010/11- 
2012/13, we were able to highlight variations over time (over a nine year period) and geographically across the different MAPPA areas in a number of ways: firstly, in the risk allocation of RSOs; secondly in the administration of SOPOs, and thirdly in the use of sanctions for non-compliance with MAPPA.

A number of tentative arguments have been put forward to account for this variation. For example, the variation in the way that risk is being assessed most likely reflects institutional differences (see also Hudson et al. 2015). The imposition of a SOPO, similarly, appears to be strongly influenced by localised preference across MAPPA areas, rather than due to the risk management level to which RSOs have been allocated there. Both explanations may reflect the cost of resourcing MAPPA practices over time. Resourcing issues could, for example, account for the apparent downwards trend in the use of higher risk categories in the risk level allocation. Our data certainly raises questions as to whether the increase in the rate at which SOPOs have been used reflects the problem of shrinking resources and a need to find a more efficient and/or cheaper alternative to 'managing' RSOs previously monitored at MAPPA levels two and three.

Clearly a limitation of using this kind of data and approach is that such explanations can only be considered to be proxies for the underlying variations. Only further detailed research, such as that undertaken in the USA (for example, Tewksbury \& Mustaine 2013), which includes local analysis, taking into account direct comparisons of offender types and practitioner attitudes and decisions across MAPPA areas would reveal this. 
However, the tentative findings presented here would suggest that further exploration and study of these issues is warranted. Crucially, we would argue that this is necessary from a human rights perspective. To reiterate, the level of risk at which a RSO is managed has implications in terms of their rights and autonomy, determining both the degree of restrictive, rehabilitative and protective interventions put in place to manage risk, and the extent to which information is shared between agencies involved in MAPPA. The apparent variations in the risk-level allocation of RSOs reinforce existing concerns surrounding the accuracy and predictability of different risk assessment tools and professional decision making techniques. The variation in the rates of level 2 and 3 RSOs and the use of SOPOs between MAPPA areas suggests an acceptability and/or tolerance of ‘false positive' outcomes, which disregard an RSO’s basic rights (Ericson, 2007; Hebenton and Seddon, 2009). While MAPPA guidance aims to negate any bias, our data clearly questions whether the guidance is clear enough to ensure that all MAPPA areas follow it in the same way.

Human rights concerns become even more pertinent when you consider the punishment for non-compliance with crime prevention measures such as SOPOs and the notification requirements. Indeed, while the compliance rate for registration is high, this may actually reflect the fact that breach of notification requirements is an offence in its own right, attracting up to five years imprisonment. Similarly, breach of court orders can demand the same sentence. While our data shows that the number of RSOs convicted or 
cautioned for breaching the notification requirements has declined, the apparent variations between the proportion of RSOs managed at MAPPA levels 2 and 3 and the sanctions for non-compliance in each MAPPA area, raises questions about fairness and legitimacy.

Recent changes made in the Anti-social Behaviour, Crime and Policing Act 2014, as well as the recommendations made in the Davies Report (Davies 2013) on civil prevention orders widens the net of who will be subject to the measures discussed in this paper. It has been argued that the changes do not pose any fundamental human rights objections (including those discussed earlier in relation to Article 8 of the ECHR, which concerns the 'Right to Respect for Private and Family Life') and that any additional restrictions or decisions to widen the net to include individuals with 'no qualifying conviction' (see for example Davies 2013) is necessary and justifiable in order to protect children and adults from sexual abuse. While this paper comes from the same purposive starting point, it raises questions over the precautionary logic that may be driving such decisions. More importantly, it recognises that while there is clearly a need to protect the public from sexual abuse and to ensure that the legislation covers all eventualities, the measures administered need to be reasonable, proportionate, just or if nothing else, appropriately targeted rather than universally applied.

It is therefore imperative that we have accurate data on MAPPA Practice. At the very least, our findings remind us that the practices of managing (and controlling) RSOs are 
a social process and are thus susceptible to variations in those practices which may not necessarily reflect their intended design and guidance. The level of variations in practice shown in this paper supports the need for further research into the consistency of MAPPA practice to ensure that the need to manage RSOs is matched appropriately to an accurate prediction of future risk.

\section{Notes}

${ }^{1}$ The Sex Offenders Register was introduced in the Sex Offenders Act 1997 and later amended in the Criminal Justice and Court Services Act (CJCSA) 2000 and the Sexual Offences Act 2003.

${ }^{2}$ MAPPA were introduced into legislation through the Criminal Justice and Courts Service Act (CJCSA) 2000 and Criminal Justice Act (CJA) 2003. These arrangements have been subject to research evaluations (Maguire et al 2001; Kemshall et al. 2005; Wood and Kemshall 2007) and guidance (see for example, Home Office 2003; 2004; 2007; MoJ 2007; 2012). MAPPA involves a tiered system of risk management of registered sexual offenders (category 1), violent offenders (category 2) and 'other dangerous offenders' (category 3) at Level 1 (low/medium risk), Level 2 (high risk) or Level 3 (critical risk). For more information see MoJ (2007; 2012).

3 These regulations increased the amount of information that RSOs are obliged to provide to the police as part of the notification requirements under the Act. 4 We are not uncritical of the use of the term 'offender' in relation to individuals who are not necessarily still involved in criminal offending and therefore use the term RSO within this paper merely due to its use as a category within the official MAPPA documentation.

${ }^{5}$ The SOPO has since been replaced by the SHPO. Other civil orders discussed do not form part of our analysis as they are used comparatively rarely.

${ }^{6}$ Although 'Claire's Law', a national domestic violence disclosure scheme, has now been implemented for violent offenders (see Strickland 2013).

${ }^{7}$ It should be noted that the term 'necessary' imports a higher threshold of consideration for courts than if such measures were merely 'desirable'. See for instance the judgements in $R v$ Halloren [2004] EWCA Crim 233, para. 14, available at: http://www.bailii.org/ew/cases/EWCA/Crim/2004/233.html and $R v$ Hemsley [2010] EWCA Crim 225, available at: http://www.bailii.org/ew/cases/EWCA/Crim/2010/225.html 
${ }^{8}$ In $R$ (on the application of $F$ (by his litigation friend F)) and Thompson (FC) (Respondents) v Secretary of State for the Home Department (Appellant) [2010] UKSC 17, available at: http://www.bailii.org/uk/cases/UKSC/2010/17.html

${ }^{9}$ Offences listed in schedule 5 are not sexual offences. Schedule 5 includes murder as well as all the offences in Schedule 15 of the Criminal Justice Act 2003, which relate to "dangerous offenders".

${ }^{10}$ See $R v$ Hammond [2008] EWCA Crim 1358, available at: http://www.bailii.org/ew/cases/EWCA/Crim/2008/1358.html.

11 This phrasing is no doubt designed to ensure compliance with article 8.2 of the ECHR.

12 The variations in risk-level allocation are explored in much greater detail in Hudson et al. (2015).

${ }^{13}$ MAPPA data were not provided on RSOs managed at level 1 ('low' or 'medium risk') who are sent to custody for breaching their SOPO.

${ }^{14}$ See Smith \& Ors, R. v (Rev 1) [2011] EWCA Crim 1772 (19 July 2011), available at http://www.bailii.org/ew/cases/EWCA/Crim/2011/1772.html

\section{References}

Barnett, G., Wakeling, H. and Howard, P.D. (2010) 'An Examination of the Predictive Validity of the Risk Matrix 2000 in England and Wales', Sexual Abuse: A Journal or Research and Treatment, 22:443-470

Bates, A.; Corbett, C.; Falshaw, L.; Friendship, C. and Patel, V. (2003) 'Assessing reconviction, reoffending and recidivism in a sample of UK sexual offenders', Legal and Criminological Psychology, 8 (2): 207-215.

Blandford, M. \& Beech, A. (2011) 'Policing sexual offenders in the community: Is it time to move from the invisible to the visible?’ in K. Doolin, J.Raine, \& A. Beech (eds.), Whose Criminal Justice? State or Community? Hampshire: Waterside Press

Bottoms, A. (1995), 'The Politics of Sentencing Reform', in C. Clarkson and R. Morgan, eds., The Philosophy and Politics of Punishment and Sentencing, 1749. Oxford: Oxford University Press.

Brayford, J. and Deering, J. (2012), 'Media Influences on Public Perceptions of Sex Offenders: Impact on Policy and Practice', in J. Brayford, F. Cowe and J. Deering, eds., Sex Offenders: Punish, Help, Change or Control? Theory, Policy and Practice Explored, 52-68. Oxford: Routledge.

Brown, S. (2010) An introduction to sex offender treatment programmes and their risk reduction efficacy. In: Harrison, K. (ed.) Managing High-Risk Sex Offenders in the Community: Risk management, treatment and social responsibility. Willan. 
Butler, L., Goodman-Delahunty, J. and Lulham, R. (2012) 'Effectiveness of Pretrial Community-Based Diversion in Reducing Reoffending by Adult Intrafamilial Child Sex Offenders', Criminal Justice and Behavior 39: 493

Chan, V., Homes, A., Murry, L. and Treanor, S. (2010), Evaluation of the Offender Community Disclosure Pilot. IPSOS MORI: Scotland

Cobley, C. (2000), Sex Offenders: Law, Policy and Practice. Bristol: Jordan.

Craig, L. A., Browne, K. D., \& Stringer, I. (2003). Risk scales and factors predictive of sexual offence recidivism. Trauma, Violence, \& Abuse, 4, 45-69.

Craig, L., Browne, K.D., and Beech, A.R. (2008), Assessing Risk in Sex Offenders: A Practitioner's Guide. Chichester: Wiley.

Craig, L. A., Beech, A. R., \& Browne, K. D. (2006). Evaluating the predictive accuracy of sex offender risk assessment measures on UK samples: A cross-validation of the Risk Matrix 2000 scales. Sexual Offender Treatment, 1(1). Retrieved June 1, 2008, from http:// www.sexual-offender-treatment.org/19.98.html

Critcher, C. (2002). Media, government and moral panic: The politics of paedophilia in Britain 2000-1. Journalism Studies, 3(4): 521-535.

Davies, H OBE QC with Beddoe, C., McCourt, S., McIntrye, J., Geden, J. DCI., and Morgan, A. DC; (2013) Civil Prevention Orders, Sexual Offences Act, ACPO Commissioned Review of the exisiting statutory scheme and recommendation for reform.

Ericson, R. V. (2007), Crime in an Insecure World. Cambridge: Polity Press

Falshaw, L., Bates, A., Patel, V., Corbett, C., and Frienship, C. (2003) 'Assessing reconviction, reoffending and recidivism in a sample of UK sexual offenders', Legal and Criminological Psychology (2003), 8, 207-215

Finkelhor, D. (2009). The prevention of childhood sexual abuse. Future of Children, 19, 169-194.

Glaser, B. (2003), 'Therapeutic Jurisprudence: An Ethical Paradigm for Therapists in Sex Offender Treatment Programs', Western Criminology Review, 4 (2): 1-16.

Greer, C. (2003), Sex Crime and the Media: Sex Offending and the Press in a Divided Society. Cullompton: Willan.

Hanson, R. K., \& Morton-Bourgon, K. (2009). 'The accuracy of recidivism risk assessment instruments for sexual offenders: A meta-analysis of 118 prediction studies'. Psychological Assessment, 21, 1-21.

Harris, A.J.R and Hanson, R.K. (2004) 'Sex Offender Recidivism: A Simple Question', Public Safety and Emergency Preparedness Canada, Available online: https://www.publicsafety.gc.ca/cnt/rsrcs/pblctns/sx-ffndr-rcdvsm/sx-ffndrrcdvsm-eng.pdf (Last accessed 18 June 2014).Hebenton, B and Seddon, T. (2009) 'From Dangerousness to Precaution: Managing Sexual and Violent Offenders in an Insecure and Uncertain Age', British Journal of Criminology, 49, 343-362 
Hoare, J. \& Jansson, K. (2008) British Crime Survey: Homicides, Firearm Offences and Intimate Violence 2006/07,'suppl.vol. 2 to Crime in England and Wales 2006/7, Home Office; London

Home Office (2003), MAPPA Guidance (Version 1). London: Home Office.

Home Office (2004), MAPPA Guidance (Version 2). London: Home Office.

Home Office (2007), MAPPA - The First Five Years: A National Overview of the Multi-Agency Public Protection Arrangements. London: Home Office.

Home Office (2012a), Guidance On Part Two Of The Sexual Offences Act 2003, London: Home Office. Available at:

https://www.gov.uk/government/uploads/system/uploads/attachment_data/file/1 17551/sexual-offences-act-2003.pdf (Accessed 20 January 2014)

Home Office (2012b), Frequently asked questions: changes to the notification requirements for registered sex offenders, London: Home Office. Available at: https://www.gov.uk/government/uploads/system/uploads/attachment_data/file/1 17552/faq.pdf (Accessed 20 January 2014).

Hudson, K.J.; Taylor, C. and Henley A.J. (2015) 'Trends in the management of Registered Sexual Offenders across England and Wales: a geographical approach to the study of sexual offending', Journal of Sexual Aggression, 21(1): 56-70

Kelly, L., Lovett, J., and Regan, L. (2005) A gap or a chasm? Attrition in reported rape cases, Home Office Research Study 293

Kemshall, H. (2008), Understanding the Community Management of High Risk Offenders. Maidenhead: McGraw-Hill/ Open University Press.

Kemshall, H., Kelly, G. and Wilkinson, B. (2012) 'Child Sex Offender Public Disclosure Scheme: The views of applicants using the English pilot disclosure scheme', Journal of Sexual Aggression, 18 (2): 164-178

Kemshall, H., Mackenzie, G., Wood, J., Bailey, R. and Yates, J. (2005), Strengthening Multi-Agency Public Protection Arrangements (MAPPAs). London: Home Office.

Kemshall, H. and Maguire, M. (2002) 'Community Justice, Risk Management and the Role of Multi-Agency Public Protection Panels', British Journal of Community Justice, 1: 11-27.

Kemshall, H. and Wood, J. (2008), 'Risk and Public Protection: Responding to Involuntary and 'Taboo' Risk', Social Policy and Administrations, 42(6): 611629.

Kemshall, H and Wood, J, (with Westwood, S., Stout, B., Wilkinson, B., Kelly, G. and Mackenzie. G). (2010), Child Sex Offender Review (CSOR) Public Disclosure Pilots: A Process Evaluation, Home Office Research Report 32. London: Home Office. 
Kershall, C. Nicholas, S and Walker, A. (2008) Crime in England and Wales 2007/08Findings from the British Crime Survey and police recorded crime, Home Office, London

Kitzinger, J. (1999), 'The Ultimate Neighbour from Hell? Stranger Danger and the Media Framing of Paedophiles'. In B. Franklin, ed, Social Policy, The Media and Misrepresentation, 207-221. London: Routledge.

Kitzinger, J. (2004a), Framing Abuse: Media Influence and Public Understanding of Sexual Violence Against Children'. London: Pluto.

Kitzinger, J. (2004b), 'Media Coverage of Violence Against Women and Children'. In K. Ross and C. M. Byerly, eds., Women and the Media: International Perspectives, 13-38. London: Blackwell.

Knock, K., Schlesinger, P., Boyle, R. and Magor, M. (2002) The Police Perspectives on Sex Offender Orders: A Preliminary Review of Policy and Practice. London: Home Office.

Maguire, M., Kemshall, H., Noaks, L. and Wincup, E. (2001), Risk Management of Sexual and Violent Offenders: The Work of Public Protection Panels. Police Research Series Paper 139. London: Home Office.

Mann, R. E., Hanson, R. K., \& Thornton, D. (2010). 'Assessing risk for recidivism: Some proposals on the nature of psychologically meaningful risk factors'. Sexual Abuse: A Journal of Research and Treatment, 22, 191-217

Ministry of Justice (2007), MAPPA Guidance 2007 (Version 2.0). Produced by the National MAPPA Team, National Offender Management Service Public Protection Unit. London: Ministry of Justice.

Ministry of Justice (2012), MAPPA Guidance 2012 (Version 4). Produced by the National MAPPA Team, National Offender Management Service Public Protection Unit. London: Ministry of Justice.

Ministry of Justice (2013a) Transforming Rehabilitation: A Strategy for Reform London: MoJ

Ministry of Justice (2013b) Transforming Rehabilitation: Target operating model, rehabilitation programme London: MoJ

Peck, Mark (2011) Patterns of reconviction among offenders eligible for Multi Agency Public Protection Arrangements (MAPPA). Ministry of Justice Series 6/11, June 2011, available at: http://www.justice.gov.uk/downloads/publications/researchand-analysis/moj-research/patterns-reconviction-mappa.pdf

Schauer, F. (2013), 'The Ubiquity of Prevention', in A. Ashworth, L. Zedner and P. Tomlin (eds), Prevention and the Limits of the Criminal Law, 10-22. Oxford: OUP.

Shute, S. (2004) New civil preventative orders: sexual offences prevention orders; foreign travel orders; risk of sexual harm orders. Criminal Law Review, 2004. May pp. 417-440. ISSN 0011-135X 
Smallbone, S., Marshall, W. L., \& Wortley, R. (2008). Preventing child sexual abuse: Evidence, policy and practice. Devon, UK: Willan.

Soothill, K., Francis, B. and Ackerley, E. (1998), 'Paedophilia and Paedophiles', New Law Journal, June 12, 882-823.

Stalans, L. J. (2004). 'Adult sex offenders on community supervision: A review of recent assessment strategies and treatment'. Criminal Justice and Behavior, 31, 564-608.

Stone, N. (2012), 'Legislation and Sex Offending', in J. Brayford, F. Cowe and J. Deering, eds, Sex Offenders: Punish, Help, Change or Control? Theory, Policy and Practice Explored, 13-33. Oxford: Routledge.

Strickland, P. (2013), “Clare's law”: the Domestic Violence Disclosure Scheme House of Commons briefing note SN/HA/6250. London: House of Commons Library. Available at: http://www.parliament.uk/business/publications/research/briefingpapers/SN06250/clares-law-the-domestic-violence-disclosure-scheme (Last accessed 19 June 2014)

Taylor, C. S., \& Gassner, L. (2010). Stemming the flow: Challenges for policing adult sexual assault with regard to attrition rates and under-reporting of sexual offences. Police Practice and Research, 11, 240-255.

Tewksbury, R., \& Mustaine, E. E. (2013). Law-enforcement officials' views of sex offender registration and community notification. International Journal of Police Science \& Management, 15(2), 95-113. doi:10.1350/ijps.2013.15.2.305

Thomas, T. (2008), 'The Sex Offender Register: A Measure of Public Protection or a Punishment in its Own Right?' Papers from the British Criminology Conference: An Online Journal by the British Society of Criminology Vol. 8: 8596. Available at: http://britsoccrim.org/new/volume8/6Thomas08.pdf (Last accessed 19 June 2014).

Thomas, T. (2011), The Registration and Monitoring of Sex Offenders: A Comparative Study. Oxford: Routledge.

Thornton, D., Mann, R., Webster, S., Blud, L., Travers, R., Friendship, C. (2003). Distinguishing and combining risks for sexual and violent recidivism. Annals of New York Academy of Sciences, 989, 225-235.

Ward, T and Connolly, M. (2008), A Human Rights-Based Practice Framework for Sexual Offenders, Journal of Sexual Aggression: An International, Interdisciplinary Forum for Research, Theory and Practice, 14 (2): 87-98.

Ward, T. and Birgden, A. (2007), Human Rights and Correctional Clinical Practice. Aggression and Violent Behavior, 12: 628-643.

Ward, T., Gannon, T. and Birgden, A. (2007), 'Human Rights and the Treatment of Sex Offenders', Sexual Abuse: A Journal of Research and Treatment, 19: 195-216. 
Wood, J. and Kemshall, H. (2008), 'Risk Management, Accountability and Partnerships in Criminal Justice: The Case of Multi-Agency Public Protection Arrangements (MAPPA)', in B. Stout, J. Yates and B. Williams, eds., Applied Criminology. London: Sage.

Wood, J. and Kemshall, H. (with Maguire, M., Hudson, K. and Mackenzie, G.) (2007), The Operation and Experience of Multi-Agency Public Protection Arrangements (MAPPA): Research and Statistics Department, online report 12/07. London: Home Office.

\section{Author biographies}

Kirsty Hudson is a Senior Lecturer in Criminology and Criminal Justice in the School of Social Sciences, Cardiff University. Her research interests include sexual offending and sex offenders, violence against women, and resettlement policy and practice.

Andrew Henley is a PhD Candidate and Graduate Teaching Assistant in the School of Sociology and Criminology, Keele University. His research interests include the legal rehabilitation of lawbreakers and the emergence of post-sentence control measures.

\section{Final word count (of all preceding material) $=8$,291 words}

\section{Contact details:}

Dr Kirsty Hudson (corresponding author)

hudsonkj@cardiff.ac.uk

SOCSI

King Edward VII Avenue

Cardiff

CF10 3WT

UK

02920874773

Andrew Henley

a.henley1@keele.ac.uk

School of Sociology and Criminology

Keele University

Keele

Staffordshire

UK

ST5 5BG

01782734143 